\title{
Home range and movements of American alligators (Alligator mississippiensis) in an estuary habitat
}

Ikuko Fujisaki ${ }^{1 *}$, Kristen M Hart ${ }^{2}$, Frank J Mazzotti ${ }^{1}$, Michael S Cherkiss ${ }^{2}$, Autumn R Sartain ${ }^{3}$, Brian M Jeffery ${ }^{1}$, Jeffrey S Beauchamp ${ }^{1}$ and Mathew Denton ${ }^{2}$

\begin{abstract}
Background: Understanding movement patterns of free-ranging top predators throughout heterogeneous habitat is important for gaining insight into trophic interactions. We tracked the movements of five adult American alligators to delineate their estuarine habitat use and determine drivers of their activity patterns in a seasonallyfluctuating environment. We also compared VHF- and satellite-tracks of one of the alligators to examine tradeoffs in data quality and quantity.

Results: All tracked alligators showed high site fidelity in the estuary, but estimated home range size and core-use areas were highly variable. Two alligators were relatively sedentary and remained in the upper stream zone. One alligator traveled to a transition zone between freshwater marsh and estuary habitat, but primarily remained in the upstream area. Two alligators traveled to the downstream zone into saline conditions and showed high salinity tolerance. Overall movement rates were highly influenced by salinity, temperature, and season. Both satellite and VHF radio telemetries resulted in similar home range, core-use area, and activity centers.

Conclusions: This study reveals consistent use of estuary habitat by American alligators. The alligators showed variations in their movement pattern and seasonal habitat, with movement attributable to environmental factors. Although satellite-derived locations were more dispersed compared to locations collected using VHF radio-tags, data collected from VHF tracking omitted some habitat used for a short period of time, indicating the effectiveness of satellite telemetry to continuously track animals for ecosystem-scale studies.
\end{abstract}

Keywords: Crocodilian, Everglades, Satellite telemetry, VHF radio telemetry

\section{Background}

Animal movements are often determined by resource need and evolutionary history, and such movements can, in turn, affect the environment as well as other organisms [1]. Data on movement patterns is critical for understanding ecological processes and informing conservation, particularly for focal species that play crucial roles in shaping ecosystem function [2-4]. Finding linkages between individual movements and the spatially and temporally heterogeneous environment can help determine drivers of animal movement [5]. However, conducting well-designed

\footnotetext{
* Correspondence: ikuko@ufl.edu

${ }^{1}$ Ft. Lauderdale Research and Education Center, University of Florida, Davie, FL, USA

Full list of author information is available at the end of the article
}

experiments to test hypotheses about the drivers of animal movements is challenging, especially for large mobile animals in remote areas.

A range of telemetry techniques make it possible to remotely observe free-ranging animals of various taxa, allowing researchers to address fundamental questions related to spatial ecology and animal behavior [3]. The selection of a particular technique depends on study species and research questions. Movements of crocodilian species, large-sized mobile aquatic predators frequently inhabiting remote areas, have been investigated with VHF radio telemetry and in-water acoustic receivers [6,7]. These telemetry techniques have revealed the ability of true navigation and adaptation of individual movement tactics [6,7] of American alligators (Alligator mississippiensis). In another 
study of American alligator home ranges in marsh habitat, researchers used radio transmitters to conduct intensive daily and weekly tracking [8]. However, such tracking is logistically challenging for monitoring movements of highly mobile species for more extended periods in remote areas.

Satellite telemetry has been recommended as a better tool to gather location data on crocodilians over extended spatial and temporal scales [9]. Recently GPS - another contender in remote telemetry techniques - was used with acoustic telemetry to track two alligators in the Everglades estuary [10] and with these tools, researchers deciphered different movement patterns between the tracked animals. Whereas GPS telemetry is a viable alternative for remotely monitoring animal movements, the lower cost and increased battery longevity is an advantage of satellite telemetry. The effectiveness of satellite telemetry to track crocodilian movements was shown for Crocodylus porosus in an estuary habitat in Cape York Peninsula, Australia [11]. However, the tracked crocodiles exhibited large scale movements around the coastline. Therefore, the effectiveness of satellite telemetry to track species movements over a smaller ecosystem-scale remained uncertain.

The American alligator is a highly mobile apex predator that resides in some remote and hard-to-access estuarine habitats. Although they primarily inhabit fresh or lowsalinity water throughout the southeastern USA, they are also known to forage in higher salinity water as long as they have periodic access to freshwater [12-14]. Alligators consume various organisms such as fish, birds, and other aquatic fauna [15], and they play a role as top-predator, keystone species, and ecosystem engineer. Due to their ecological importance, alligators have been used as an indicator of ecosystem restoration in south Florida [16]. Because alligators have dominant top-down effects, understanding their movement behavior is especially important for interpreting the trophic interactions in a system [10].

Historically in the Everglades, Florida, American alligators were most abundant in freshwater sloughs and oligohaline (brackish water) mangrove areas [17]. However, due to the loss of wetlands and altered hydrology in the area, the spatial pattern of their habitat use has changed [14]. Alligators now primarily inhabit central sloughs and canals [18] from upstream marshes to the mouth of Shark River estuary $[7,14,18]$. Within this habitat matrix, alligators develop individual movement tactics that result in nutrient exchanges between marine, estuarine, and freshwater zones $[7,10]$.

Distinct dry and wet seasons cause seasonal dry-downs of interior marsh habitat in south Florida. As an aquatic reptile, alligators need to obtain access to freshwater sources and this seasonal fluctuation of surrounding resources likely affects their movements. Therefore, we used satellite telemetry to study individual home ranges and evaluate the relative importance of spatial and temporal factors in alligator movement patterns. To further examine the utility of satellite telemetry, we also compared results for one alligator using satellite- and VHF radiotelemetry datasets.

\section{Results}

Alligator locations and salinity data

We placed satellite tags on one female (F1) and four male (M1 to M4) adult alligators, ranging from 221 to $250 \mathrm{~cm}$ total length, caught in the Shark River estuary (Figure 1 and Table 1). We tracked the alligators from March 2009 to April 2012; the mean tracking duration was 278.6 days (SD: 108.7 days), and ranged from 163 to 399 days. The mean number of high-quality class 3 satellite locations (LC3) used for analysis was 149.6 (SD: 151.8, range: 19-341; Table 2).

We captured the female (F1) and two of three males (M1 and M2) in the less saline upstream zone, and they remained there throughout their tracking durations (Figure 1). We captured the two other males (M3 and M4) in the mid-estuary and downstream zones, respectively, and they ranged across wider areas comprising high salinity zones near the Gulf. All alligators remained in the estuary throughout their tracking periods except for M1 whose home range included both estuary and marsh habitat in a transition zone about $9 \mathrm{~km}$ upstream from the original capture location; this marsh was generally dominated by sawgrass (Cladium jamaicense).

Salinity was highly varied spatially and temporally in the study area. According to the four water gages, the salinity gradient followed the freshwater flow from the upper Shark River downstream from low to high, ranging from less than 1 ppt to 38 ppt (Figure 2). During the study period, in the upstream water gage $(\mathrm{CN})$, daily salinity values ranged from 0.15 to $25.04 \mathrm{ppt}$ (mean $2.73 \pm 4.71 \mathrm{ppt}$ ) whereas in the downstream zone daily salinity values ranged from 16.08 to 38.38 ppt (mean $28.32 \pm 4.47 \mathrm{ppt}$ ). For all water gages, the highest salinity was recorded during spring to early summer between May 30 and June 6.

\section{Home range, movement, and environmental variables}

All alligators displayed site-fidelity to their home ranges. A random walk site-fidelity test showed that the observed movements of all five alligators were more constrained than random movement paths within Everglades National Park (ENP). The proportion of the random movement paths with higher mean square distance values than the observed path was greater than 0.988 for all alligators.

Two alligators, M3 and M4, had a comparably large number of daily locations over multiple seasons: seasons $1,2,3$, and 4 for M3 and seasons 1, 2, and 4 for M4. A Kruskal-Wallis test indicated a significant difference $(P<0.001)$ in latitude and longitude by season for both alligators. The Boferroni multiple comparisons test 


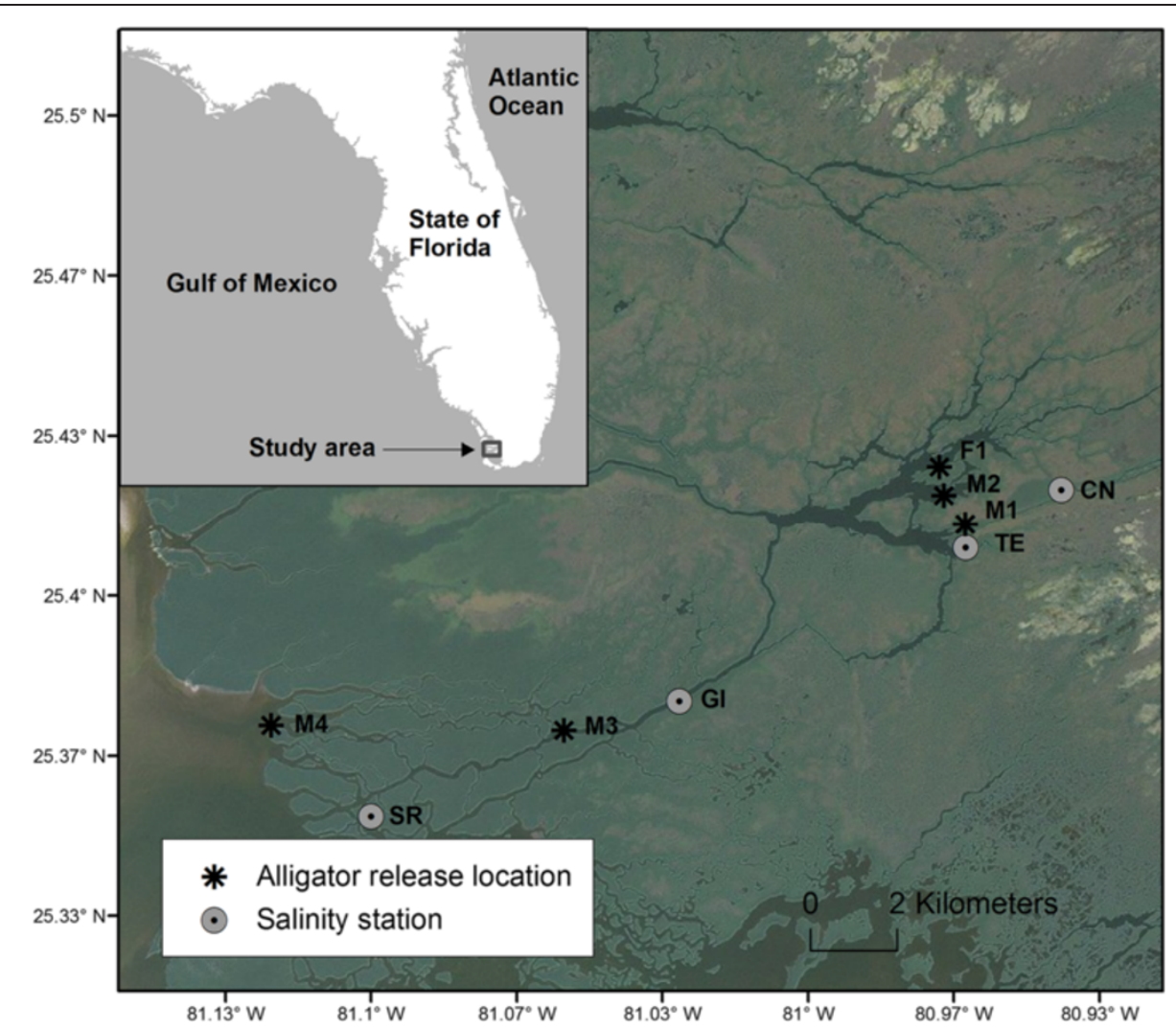

Figure 1 Map of Shark River estuary in Everglades National Park, Florida showing capture and release locations of satellite-tagged American alligators (Alligator mississippiensis) and locations of gaging stations (Shark River (SR), Gunboat Island (GI), Tarpon Bay East (TE), and Cane Patch (CN)). The inset box indicates the study area location within Florida.

showed that both latitude and longitude were significantly different $(P<0.05)$ for all pair-wise comparisons except seasons 3 and 4 for M3 and seasons 1 and 2 for M4. These seasons were combined in calculating kernel density estimates (KDE). Home range and core-use area contours from the KDEs were successfully created for all alligators (Figure 3). The bandwidth that minimized least square cross validation (LSCV) ranged from 123.0 to $489.3 \mathrm{~m}$ (mean 261.0 $\pm 120.4 \mathrm{SD}$ ) (Table 2). The size of the core-use areas (that is, $50 \% \mathrm{KDE}$ ) for the five alligators ranged from 0.5 to $8.8 \mathrm{~km}^{2}$ (mean $2.9 \pm 3.0 \mathrm{SD}$ ) and the home ranges (that is, 95\% KDE) were 2.7 to $33.1 \mathrm{~km}^{2}$ (mean: 13.1 \pm 11.9 SD; Table 2). Durations of tracking period did not correlate significantly with core- use areas $(r=-0.55, P=0.153)$ and home ranges $(r=-0.61$, $P=0.107)$. All home ranges were concentrated in riverine habitat (Figure 3).

On average, alligators moved from 0.7 to $3.2 \mathrm{~km}$ per day (mean $1.5 \pm 1.2 \mathrm{SD}$ ) and the daily movement was significantly different between animals $(K=12.8, P=0.012)$. The null model of daily movement resulted in considerably higher corrected Akaike Information Criterion (AICc) compared to all other parameterized models (Table 3). The top model with the smallest AICc was one of the most parameterized models that included salinity, season, maximum temperature $\left(T_{\max }\right)$, and an interaction term of $T_{\max }$ and season. The AICc weight of this model $(>0.99)$ implies that there is a great probability that this is the true model

Table 1 Summary of satellite-tracked American alligators (Alligator mississippiensis), including tracking period, sex, total length (TL), snout vent length (SVL), and weight, in Shark River estuary in Everglades National Park, Florida

\begin{tabular}{|c|c|c|c|c|c|c|}
\hline ID & Date deployed & Last date of observation & Sex & $\mathrm{TL}(\mathrm{cm})$ & SVL $(\mathrm{cm})$ & Weight (kg) \\
\hline F1 & 27 October 2011 & 2 August 2012 & Female & 221.1 & 111.6 & 27 \\
\hline M1 & 27 March 2009 & 29 August 2009 & Male & 243.6 & 126.8 & 45 \\
\hline$M 2$ & 29 October 2011 & 17 November 2012 & Male & 244.0 & 125.2 & 46 \\
\hline M3 & 3 November 2011 & 11 November 2012 & Male & 245.4 & 126.3 & 45 \\
\hline M4 & 3 November 2011 & 27 April 2012 & Male & 250.0 & 131.1 & 48 \\
\hline
\end{tabular}


Table 2 Summary of satellite data and movement parameters, kernel size $\left(h_{\text {Iscvi }}\right.$ estimated using fixed kernel least square cross validation (LSCV)), and areas of $50 \%$ and $95 \%$ kernel contours, derived using LC3 data

\begin{tabular}{|c|c|c|c|c|c|c|}
\hline ID & Season & Detections (n) & Days with detection (n) & $h_{\text {Iscv }}(m)$ & Area of $50 \% \mathrm{KDE}\left(\mathrm{km}^{2}\right)$ & Area of $95 \% \mathrm{KDE}\left(\mathrm{km}^{2}\right)$ \\
\hline$\overline{F 1}$ & All & 19 & 18 & 163.7 & 0.54 & 2.95 \\
\hline M1 & All & 52 & 42 & 201.5 & 0.55 & 2.85 \\
\hline M2 & All & 49 & 40 & 317.6 & 1.35 & 5.58 \\
\hline \multirow[t]{3}{*}{ M3 } & 1 & 66 & 39 & 168.6 & 0.47 & 2.69 \\
\hline & 2 & 76 & 50 & 327.9 & 3.83 & 21.23 \\
\hline & $3 \& 4$ & 199 & 119 & 293.3 & 5.39 & 25.36 \\
\hline \multirow[t]{2}{*}{ M4 } & $1 \& 2$ & 198 & 96 & 123.0 & 1.87 & 10.94 \\
\hline & 4 & 89 & 41 & 489.3 & 8.84 & 33.11 \\
\hline
\end{tabular}

Kernel density estimates (KDE) were calculated with all location data for $\mathrm{F} 1, \mathrm{M} 1$, and $\mathrm{M} 2$, and by season for $\mathrm{M} 3$ and $\mathrm{M} 4$, where season 1 is from January to March, season 2 is from April to June, season 3 is from July to September, and season 4 is from October to December.

among all competing models. Type III test of fixed effects indicated that salinity $\left(F_{1,210}=5.42, P=0.021\right)$, season $\left(F_{3,210}=2.72, P=0.046\right)$, and the interaction of season and $T_{\max }\left(F_{3,210}=2.85, P=0.038\right)$ significantly affected daily movement for the alligators. Daily movement was higher when daily salinity was higher $\left(B_{\text {salinity }}=51.8 \pm 22.2 \mathrm{SE}\right)$.

\section{Comparing satellite and VHF radio telemetries}

Both the VHF and satellite tags on alligator M1 transmitted long enough for a comparison of effectiveness. The satellite tag stopped transmitting on 28 August, 154 days after the release. The VHF continued to transmit a signal as of 9 October 2009 (196 days after release). In total, 22 biweekly flights were performed to track the alligator with the VHF signal, resulting in 22 locations. During the same period, 226 satellite locations were recorded from 92 unique days.
Using only data with LC3, 39 satellite-tracked locations from 35 unique days were available for analysis.

All satellite- and VHF-tracked locations were along the upper estuary zone, however, it appeared that VHF surveys missed the habitat used in a further upstream area where M1 traveled during a 2-week VHF survey interval (Figure 4). High-quality satellite-tracked locations tended to be spatially more sparse than VHF-derived locations; standard deviations in both easting and northing UTMs of satellite-derived locations were much larger $(818.0 \mathrm{~m}$ for easting and $513.8 \mathrm{~m}$ for northing) than those derived from VHF surveys (136.9 $\mathrm{m}$ for easting and $225.4 \mathrm{~m}$ for northing). This is, in part, because satellite telemetry detected the secondary habitat that M1 used for a short-period.

Using a $200 \mathrm{~m}$ bandwidth, approximately the bandwidth that minimized LSCV with satellite data (Table 2), satellitetracked locations resulted in larger KDEs $\left(2.58 \mathrm{~km}^{2}\right.$ for

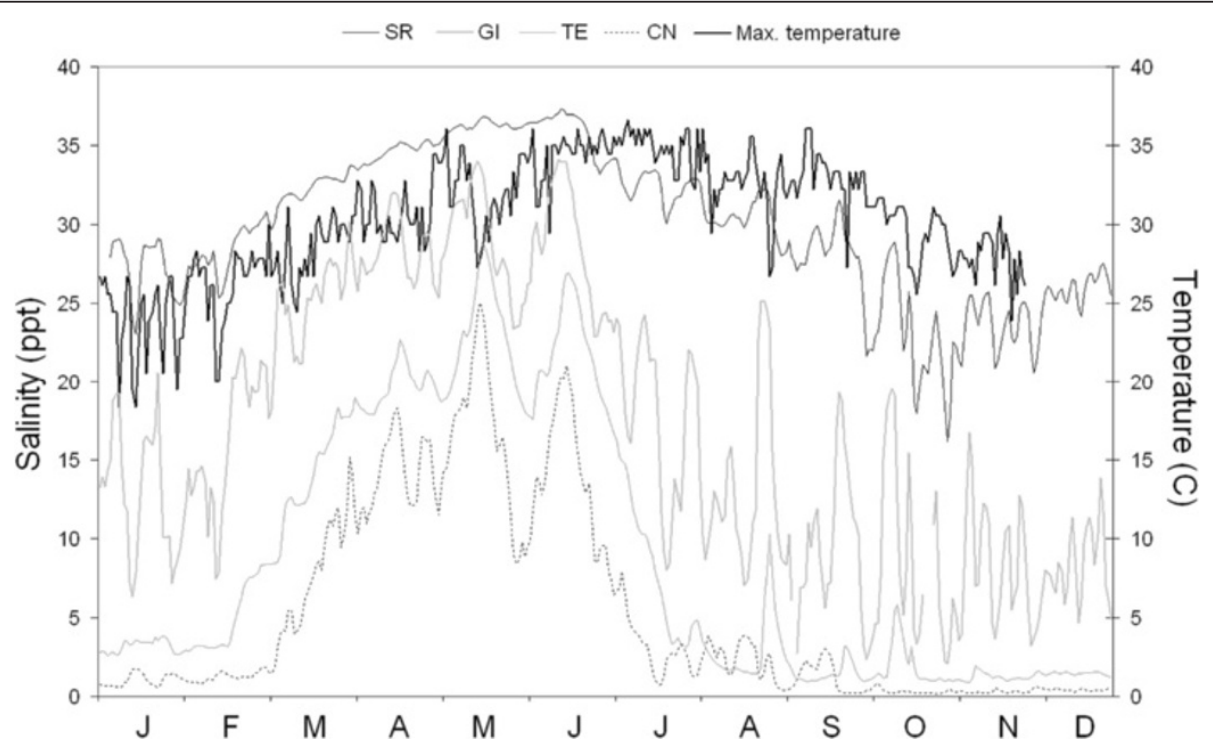

Figure 2 Daily salinity at four monitoring gages placed in Shark River estuary (Shark River (SR), Gunboat Island (GI), Tarpon Bay East (TE), and Cane Patch (CN, see Figure 1)) and daily maximum air temperature in Everglades National Park in 2011. 


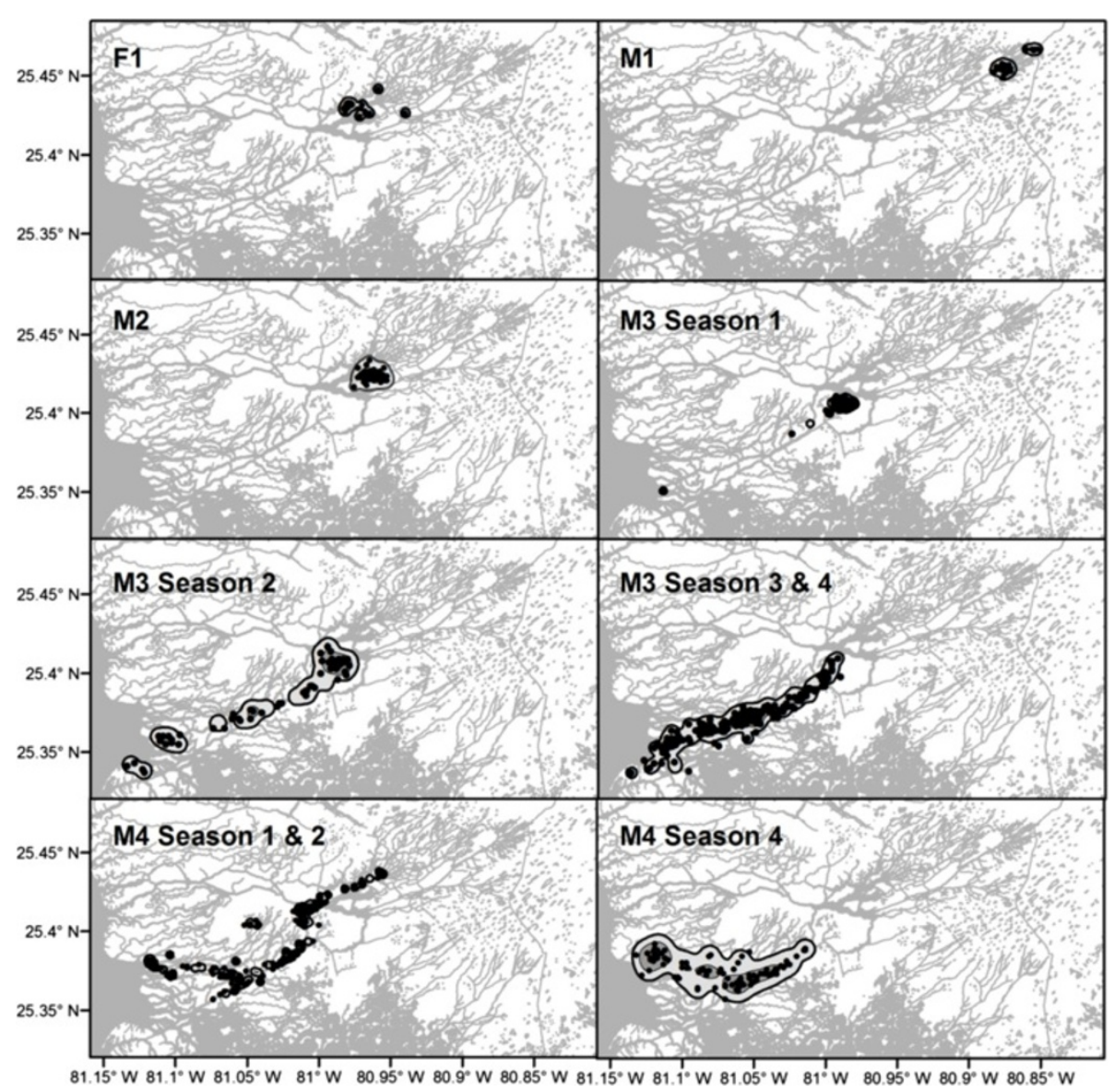

Figure 3 Satellite locations (dark points), estimated core-use areas ( $50 \%$ kernel density contour; darker tone), and home ranges (95\% kernel density contour; lighter tone) of one female (F1) and four male (M1, M2, M3, and M4) American alligators (Alligator mississippiensis) tracked using satellite telemetry in the Shark River estuary, Everglades National Park. Kernel density estimates (KDE) were calculated with all location data for $\mathrm{F} 1, \mathrm{M} 1$, and $\mathrm{M} 2$, and by season for $\mathrm{M} 3$ and $\mathrm{M} 4$, where season 1 is from January to March, season 2 is from April to June, season 3 is from July to September, and season 4 is from October to December.

Table 3 Results of the model comparison using corrected Akaike Information Criterion (AICC)

\begin{tabular}{lccc}
\hline Model & AICc & $\Delta$ AICc & AICc weight \\
\hline Salinity, season, $T_{\max } \times$ season, $T_{\max }$ & $4,020.4$ & 0 & $>0.999$ \\
Salinity, season, salinity $\times$ season, $T_{\max }$ & $4,031.7$ & 11.3 & $<0.001$ \\
Salinity, season, $T_{\max }$ & $4,064.1$ & 43.7 & $<0.001$ \\
Season, $T_{\max }$ & $4,094.5$ & 74.1 & $<0.001$ \\
Salinity, $T_{\max }$ & $4,131.7$ & 111.3 & $<0.001$ \\
$T_{\max }$ & $4,161.1$ & 140.7 & $<0.001$ \\
Salinity, season, salinity $\times$ season & $4,386.2$ & 365.8 & $<0.001$ \\
Salinity, season & $4,418.1$ & 397.7 & $<0.001$ \\
Season & $4,453.9$ & 433.5 & $<0.001$ \\
Salinity & $4,499.6$ & 479.2 & $<0.001$ \\
Null & $4,531.6$ & 511.2 & $<0.001$ \\
\hline
\end{tabular}

Null model is the intercept model. All models included random effect of alligators. The symbol $\times$ denotes interaction effect.
95\% KDE and $0.52 \mathrm{~km}^{2}$ for $\left.50 \% \mathrm{KDEs}\right)$ than those calculated with VHF-tracking locations $\left(1.36 \mathrm{~km}^{2}\right.$ and $\left.0.24 \mathrm{~km}^{2}\right)$. Both the VHF-derived and satellite-derived core-use areas were in similar locations and the satellite-derived core-use areas contained the vast majority (97\%) of the VHF-derived core-use area. Centroids of the 50\% KDEs from both tracking methods were about $150 \mathrm{~m}$ apart (Figure 4).

\section{Discussion}

Our study depicts variation in the home range and movement patterns of satellite-tracked alligators. Although the results may be partially attributed to differences in tracking duration and the number of satellite-derived locations $[19,20]$, the presence of variation between individuals and by season are clear. In a previous study in the same location, researchers used stationary in-water acoustic receivers and theorized that a large portion of tagged alligators likely left the monitored area for marsh habitat [7]. All of our alligators exhibited quantifiably high site 


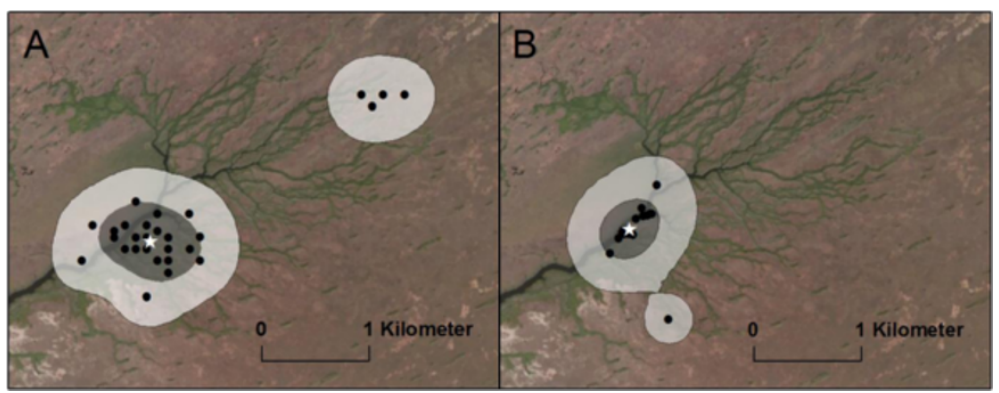

Figure 4 Observed locations (black dots) and estimated kernel density contours of a male alligator (M1) using satellite (A) and VHF radio telemetries (B). Darker and lighter tone polygons are 50\% and $95 \%$ kernel contours, respectively. Stars represent the centroid of the $50 \%$ kernel contours.

fidelity to the riverine areas, indicating that our tagged alligators were resident in the estuary during the monitored periods. However, one alligator (M1) traveled further north to a transition zone between river and freshwater marsh for a short period, which is not inconsistent with the previous study [7]. Within the estuary, alligators showed highly variable habitat use patterns. Satellite-tracked alligators either remained in the mid- to upper-estuary brackish water (F1, M1, and M2) or traveled intermittently to the downstream zone adjacent to the Gulf (M3 and M4). Whereas our alligators may not have left the monitored area as presumed in the previous study, the movements we discovered are consistent with the findings of that study, as they demonstrated that alligators adapt their movement tactics in a heterogeneous estuarine habitat [7].

Overall, the daily movements we estimated were much higher than previous rates from marsh and canal habitats in south Florida [8] but were comparable with the range of individuals estimated by acoustic telemetry in the same study area [10]. Previous studies have shown that alligator movements vary by ecological system and individual traits. Several of these studies showed alligators have a relatively sedentary nature $[8,21]$, whereas others showed their capability of long-distance travel $[22,23]$. Our results, combined with those in previous studies, suggests that alligator movement and home range behavior are influenced by habitat as well as individual specialization in foraging tactics and prey preference $[7,10]$.

Whereas this study is based on a small number of tagged alligators, the results indicate that their movement rate is attributed to a number of environmental factors. Salinity is one factor in the environment that could influence alligator movements. Adult alligators can tolerate high salinity water as long as they have periodic access to freshwater $[24,25]$. The salinity measured near the mouth of the estuary (station SR; Figure 1), where two male alligators (M3 and M4) traveled, became as high as $30.7 \mathrm{ppt}$ (mean 25.0 $\pm 2.6 \mathrm{SD}$ ). Previous researchers have described daily, relatively short distance excursions into sea water by alligators, presumably to feed $[24,25]$. What recent studies
$[7,26]$ discovered, and we confirmed, is that alligators make longer distance movements to marine conditions for longer periods of time, also presumably to feed. Large alligators have some tolerance to saline conditions as long as through diet, rainwater, or movement they do not become dehydrated [27]; feeding on vertebrate prey would ease the osmotic burden of a sea-going alligator. In our study, it did appear that adult alligator movement was influenced by the salinity of estuarine water, as daily movement rates increased when salinity increased.

Our result is consistent with previous studies of alligator home range and movements in which seasonal variation was found [28]; in spring, both males and females showed increased movement rates in a north central Florida lake. Male alligators in a coastal marsh in Louisiana are known to extend range size and movement rate during the spring breeding season [22]. During summer, alligators tend to reduce activity range [28], likely due to increased metabolic costs under increased ambient temperature [29]. Likewise, we found alligator movements were influenced by season, temperature, and the interaction of these two factors.

Satellite telemetry was an effective tool that enabled us to decipher the movements of alligators at our study site. In general satellite telemetry can be useful for understanding ecosystem-scale habitat use and movement patterns of wildlife. It has been prevalent in studies on large scale movements of free-ranging animals, such as migratory birds [30] and large marine vertebrates such as whales [31], seals [32], and sea turtles [33,34]. These species frequently travel long distances across different climatic zones or even make continental movements (for example, [35]) in which potential location errors are comparably minor. Although in some cases alligators exhibited long distance travel with dispersal into different systems [36], their movement scale is typically smaller. To account for the smaller scale and minimize location errors in our dataset, we used only the highest quality location data (LC3).

From this high-quality satellite data, we delineated relatively small-sized core-use areas and home ranges of 
alligators in the Everglades estuary. Although direct comparison is not relevant due to differences in both field and analytical approaches (LC 3 locations of satellite telemetry can be off by $250 \mathrm{~m}$ ), it appeared that the estimated coreuse area $\left(0.54-1.35 \mathrm{~km}^{2}\right)$ of the three alligators that remained in small ranges (F1, M1, and M2) was comparable to the core-use areas of marsh $\left(0.3 \mathrm{~km}^{2}\right)$ and canal $\left(0.43 \mathrm{~km}^{2}\right)$ alligators previously estimated using radio telemetry [8]. In contrast, the other two males (M3 and M4) exhibited much larger seasonal core-use areas (0.47$8.84 \mathrm{~km}^{2}$ ) than the radio telemetry-tracked alligators.

Due to logistical reasons, comparison between satellite and VHF telemetries was based on a single animal for a limited term. However, this comparison elucidated several issues that need to be considered when selecting a tracking technique. The highest-quality satellite-derived locations were more dispersed than VHF locations which resulted in a larger home range and core-use area estimate for the satellite data. However, both telemetry methods pinpointed the same general home range, core-use area, and location and number of activity centers for alligator M1. Continuous observation with satellite telemetry also enabled us to detect the use of a secondary habitat where the alligator traveled for a short time during 2 weeks with no VHF flight. Although reduced location accuracy is a drawback of satellite telemetry, its clear advantage, in addition to cost effectiveness and less labor intensity, is that it allows finer temporal observations of tracked animals compared to VHF telemetry. These finer temporal observations of satellite telemetry are also an advantage over acoustic telemetry at fixed locations. Currently, various telemetry methods are available to track free-ranging animals, but selection of a method is frequently limited by logistics. For example, GPS telemetry offers improved location accuracy with 24 hours of global coverage [37], but its high cost could lead to a necessary reduction in sample size for a given study [7].

\section{Conclusions}

Using satellite telemetry, we delineated alligator home ranges and core-use areas and quantified high site fidelity within the estuary habitat in our study site. We also found inter-estuary movements to areas of high salinity by some alligators, suggesting individual variation in habitat use. Even though American alligators occupy estuarine habitat as only a small portion of their entire range, consistent use of such habitat by satellite-tracked alligators highlights its importance for this top predator and ecosystem engineer. Our study area is influenced by water management practices in the upstream zone and water flows have been dramatically modified in the past for development [38]. Understanding habitatinfluenced movements as well as individual variation in movements and home range behaviors of alligators provides insight for system-wide planning, management and conservation.

\section{Methods}

Study area

The study was conducted in the Shark River estuary within ENP, Florida (Figure 1). Shark River slough is a major flow way in ENP. The upper slough is a freshwater wetland built upon a natural depression containing peat soils. The lower slough is a mangrove estuary. In the estuary, mangrove forests dominate primary production. Salinity gradients are influenced by rainfall, tide, and freshwater flow into Shark River that is in part determined by water management activities [39].

\section{Data}

We captured alligators in the Shark River estuary between March 2009 and March 2012 using wire-nooses as described previously [40]. We measured each animal for total length (TL), snout-vent length (SVL), and weight. We also determined sex and noted any abnormalities or deformities. We tagged alligators using unique Florida Fish and Wildlife Conservation Commission web tags, and affixed both a SPOT5 satellite tag (Wildlife Computers, $2 \times$ AA stacked, $71.5 \times 34.0 \times 24.4 \mathrm{~mm})$ and a VHF radio tag (Holohil models SI-2, $11 \mathrm{~g}$ ) to each one. For alligator M1, we attached the SPOT5 transmitter using stainless steel wire placed through the nuchal scutes and PVC tubing. We then reinforced it with a two part epoxy. For the remaining four individuals, we attached the SPOT5 transmitter as in a previous study [41]. We programmed the tags to be on continuously, and upon completion of attachment we released all individuals at their original capture location. Location data from the satellite tags was received online using Satellite Tracking and Analysis Tool (STAT) [42]. For alligator M1, weekly VHF monitoring flights were performed from a fixed-wing aircraft (Cesna 182), flying at speeds between 100 and $140 \mathrm{~km} / \mathrm{h}$ at altitudes between 152 and $610 \mathrm{~m}$. We used a Habit Osprey VHF telemetry receiver and two $\mathrm{H}$ antennas, one mounted to each wing of the airplane, to monitor telemetry signals. Once we identified where the signal was strongest, we took additional steps to ensure our location was accurate. To do this we chose a landmark where the signal strength was greatest. We then approached this spot from several directions, isolating the signal with one antenna at a time, making it possible to know which side of the plane the signal was coming from. After confirming the location of the strongest signal, we took a final pass over the landmark and recorded the location using the handheld GPS unit. We did not visually identify tagged animals due to difficulty in observing animals from the aircraft. 
Daily salinity measurements were automatically recorded at four gaging stations (Figure 1) in the Shark River estuary and retrieved from the U.S. Geological Survey South Florida Hydrology Database (GHA, TJS and KMB, unpublished work). The gages were located from 2.5 to $7.5 \mathrm{~km}$ apart spanning the upper stream to the mouth of the river. We used air temperature data from a weather station (Everglades station maintained by Florida Climate Center) located about $55 \mathrm{~km}$ straight-line distance $\left(25.85^{\circ} \mathrm{N},-81.38^{\circ} \mathrm{W}\right)$ from the study area; this station records daily minimum and maximum temperatures.

\section{Estimating home range and core-use area}

We used STAT [42] to filter location data by location quality and movement speed. With the Argos system, each satellite-detected location is associated with one of six LCs. Estimations of the location accuracy is, 3, 2, 1, $0, \mathrm{~A}, \mathrm{~B}$, and $\mathrm{Z}$, in order from best to worst. Due to the relatively small movement range we anticipated, we only used the highest quality location data, LC 3, which has the estimated location accuracy within $250 \mathrm{~m}$ [43]. We also filtered out locations with movement speeds greater than $5 \mathrm{~km}$ per hour.

To test site fidelity, we conducted Monte Carlo Random Walk simulations using Animal Movement Analysis Extension for ArcView 3.2. We generated 1,000 random paths and tested whether the observed movement paths for each animal were more spatially constrained than these random paths [44]. We bounded the paths at the $10 \mathrm{~m}$ isobath within Everglades National Park, which comprises major freshwater wetland and estuary habitat.

To determine core-use areas, we generated daily mean locations for each alligator from the filtered locations; this minimized potential autocorrelation due to multiple observations close together in time. Following previous studies [45,46], we applied fixed kernel LSCV to KDEs using the Home Range Tool with ArcGIS 9.3 [47]. We considered $50 \%$ contour areas to be core-use areas and 95\% contour areas to be home ranges for individual alligators. For alligators with a large number of locations in multiple seasons, we conducted a Kruskal-Wallis test followed by a Bonferroni multiple comparison to detect differences in latitude and longitude between seasons. If the seasonal difference in the coordinates was significant, we created separate KDEs for each season. We calculated Pearson's correlation coefficient $(r)$ between duration of tracking period and core-use area and home ranges to examine effects of the duration on the estimated areas.

Based on nesting chronology and phenology of alligators [14] and the annual rainfall patterns, we defined four seasons: winter to early spring dry season (January to March, season 1), spring to early summer wet season when courtship and nesting occur (April to June, season 2), wet season incubation and hatchling period in summer (July to September, season 3), and fall to early winter transition period from wet to dry season (October to December, season 4).

\section{Assessing relationship between movement rate and environmental variables}

We calculated daily movement distances using daily mean locations from consecutive days. We defined salinity for each daily mean location from the daily salinity recorded at the gage nearest to each location. Daily minimum and maximum temperatures recorded at the weather station were highly correlated $(r=0.99)$, and alligator movements may be constrained by the high metabolic cost under high ambient temperature [29] so we chose to use daily maximum temperature $\left(T_{\max }\right)$. We used the resulting daily movement distance and salinity data to test the effect of salinity, season, and temperature on the movement rates of the five alligators, as well as for the Kruskal-Wallis to test the differences in the daily movement rates between individuals.

We tested 11 models built upon biological hypotheses. The null model (intercept model) assumed that the difference in daily movement is merely a function of individual difference (that is, a random effect). The single factor model assumed that the movement difference was influenced by one of three factors: season, salinity, or $T_{\max }$. The two factor model assumed that combinations of salinity and season, $T_{\max }$ and season, and salinity and $T_{\max }$ independently influenced movement, but did not interact. The three factor model assumed that the movement rate was influenced by single factors of salinity, season, and $T_{\max }$, or salinity, season and an interaction of salinity and season. Finally, we tested two four-factor models which included salinity, season, $T_{\max }$ and salinity and season interaction or $T_{\max }$ and season interaction. Differences between alligators were accounted for as a random effect and were included in all models. We fitted the model using SAS MIXED procedure and calculated AICc, $\triangle \mathrm{AICc}$, and AICc weight for model comparison. Following [48] we considered that $\triangle \mathrm{AICc}<2$ indicated substantial model support, values of 4-7 indicated considerably less support, and values $>10$ had no support.

\section{Comparing satellite and VHF telemetries}

We compared satellite- and VHF radio-derived home ranges and core-use areas, as defined by $95 \%$ and $50 \%$ KDE contours, using location data for the male alligator (M1) on which both tags were deployed. Since kernel density estimators depend on the choice of bandwidth, we used the same bandwidth for both satellite and VHF data. This allowed us to assess any difference the telemetry method had on the home range and core-use area 
estimates. For this comparison, we used satellite data only during the period when VHF surveys were conducted. We used only satellite data with LC 3 (the best location class) and derived the daily mean location to minimize location error and spatial correlation.

\section{Competing interests}

The authors declare that they have no competing interests.

\section{Authors' contributions}

IF performed data analysis and wrote the draft of the paper. $\mathrm{KMH}$ initiated the study and contributed to the writing. MSC oversaw field work and contributed to the writing. FJM contributed to the writing. ARS prepared data for analysis and contributed to the writing. $\mathrm{BJ}, \mathrm{JB}$, and $\mathrm{MD}$ conducted field work. All authors read and approved the final manuscript.

\section{Acknowledgements}

Funding was provided by the Greater Everglades Priority Ecosystems Science program of the U.S. Geological Survey, the U.S. Army Corps of Engineers and Lacoste/Save Your Logo FDB. Research and collecting permits were issued by the Florida Fish and Wildlife Conservation Commission (SPGS-13-58) and Everglades National Park (EVER-2012-SCI-0010), and research methods were approved by the Institutional Animal Care and Use Committee of the University of Florida (IFAS ARC 005-12FTL) and are available for review. We also thank Rafael Crespo, Edward Larrivee, and Thomas Selby for assistance with alligator capture and transmitter attachment. Any use of trade, product or firm names is for descriptive purposes only and does not imply endorsement by the U.S. Government.

\section{Author details}

${ }^{1}$ Ft. Lauderdale Research and Education Center, University of Florida, Davie, FL, USA. ${ }^{2}$ U.S. Geological Survey, Southeast Ecological Science Center, Davie, FL, USA. ${ }^{3}$ CNTS, contracted to U.S. Geological Survey, Southeast Ecological Science Center, Davie, FL, USA.

Received: 24 January 2014 Accepted: 2 May 2014

Published: 19 May 2014

\section{References}

1. Nathan R, Getz WM, Revilla E, Holyoak M, Kadmon R, Saltz D, Smouse PE: A movement ecology paradigm for unifying organismal movement research. Proc Natl Acad Sci U S A 2008, 105:19052-19059.

2. Lambeck RJ: Focal species: a multi-species umbrella for nature conservation. Conserv Biol 1997, 11:849-856.

3. Cooke SJ, Hinch SG, Wikelski M, Andrews RD, Kuchel $\sqcup$, Wolcott TG, Butler PJ: Biotelemetry: a mechanistic approach to ecology. Phil Trans R Soc B 2010, 365:334-343.

4. Nicholson E, Lindenmayer DB, Frank K, Possingham HP: Testing the focal species approach to making conservation decisions for species persistence. Divers Distrib 2013, 19:530-540.

5. Avgar T, Mosser A, Brown GS, Fryxell JM: Environmental and individual drivers of animal movement patterns across a wide geographic gradient. J Anim Ecol 2013, 82:96-106.

6. Rodda GH: Homeward paths of displaced juvenile alligators as determined by radiotelemetry. Behav Ecol Sociobiol 1984, 14:241-246.

7. Rosenblatt $A E$, Heithaus MR: Does variation in movement tactics and trophic interactions among American alligators create habitat linkages? $J$ Anim Ecol 2011, 80:786-798.

8. Morea CR: Home Range, Movement, and Habitat use of the American Alligator in the Everglades. MS Thesis. Gainesville, FL: University of Florida; 1999.

9. Kay WR: Movements and home ranges of radio-tracked Crocodylus porosus in the Cambridge Gulf region of Western Australia. Wildl Res 2004, 31:495-508.

10. Rosenblatt AE, Heithaus MR, Mazzotti FJ, Cherkiss M, Jeffery BM: Intra-population variation in activity ranges, diel patterns, movment rates, and habitat use of American alligators in a subtropical estuary. Estuar Coast Shelf Sci 2013, 135:182-190.

11. Read MA, Grigg GC, Irwin SR, Shanahan D, Franklin CE: Satellite tracking reveals long distance coastal travel and homing by translocated estuarine crocodiles, Crocodylus porosus. PLoS One 2007, 2:e949.
12. Lauren D: The effect of chronic saline exposure on the electrolyte balance, nitrogen metabolism, and corticosterone titer in the American alligator, Alligator mississippiensis. Comp Biochem Physiol 1985, 81A:217-223.

13. Dunson W, Mazzotti FJ: Salinity as a limiting factor in the distribution of reptiles in Florida Bay: a theory for the estuarine origin of marine snakes and turtles. Bull Mar Sci 1989, 44:229-244.

14. Mazzotti F, Brandt LA: Ecology of the American Alligator in a Seasonally Fluctuating Environment. In Everglades: The Ecosystem and Its Restoration. Edited by Davis D, Ogden J. Delray Beach, FL: St. Lucie Press; 1994:485-505.

15. Barr B: Food habits of the American Alligator, Alligator mississippiensis, in the Southern Everglades. Ph. D. thesis. Coral Gables, FL: University of Miami; 1997.

16. Mazzotti FJ, Best GR, Brandt LA, Cherkiss MS, Jeffery BM, Rice KG: Alligators and crocodiles as indicators for restoration of Everglades ecosystems. Ecol Indic 2009, 9S:S137-S149.

17. Craighead FC: The role of the alligator in shaping plant communities and maintaining wildlife in the southern Everglades. Fla Nat 1968, 31:2-7. 69-74, 94.

18. Kushlan JA: Wetlands and wildlife, the Everglades perspective in Freshwater wetlands and wildlife. In conf-8603101, DOE Symposyum Series NO 61. Edited by SHaritz RR, Gibbons JW. Oak Ridge, TN: Office of Scientific and Technical Information, U.S. Department of Energy; 1990.

19. Fieberg J: Utilization distribution estimation with weighted kernel density estimators. J Wildlife Manage 2007, 2007:1669-1675.

20. Rowcliffe MJ, Carbone C, Roland K, Kranstauber B, Jansen P: Bias in estimating animal travel distance: the effect of sampling frequency. Meth Ecol Evol 2012, 3:653-662.

21. Hines TC, Fogarty MJ, Chappell LC: Alligator research in Florida: a progress report. Proc Southeastern Assoc Game Fish Commissioners 1968, 22:166-180.

22. Joanen $T$, McNease $L: A$ telemetric study of adult male alligators on Rockefeller Refuge, Louisiana. Proc Southeastern Assoc Game Fish Commissioners 1972, 26:252-275.

23. Valentine JM Jr, Walther JR, McCartney KM, Ivy LM: Alligator diets on the Sabine National Wildlife Refuge. J Wildl Manage 1972, 36:809-815.

24. Jacobsen T: Crocodilians and islands: status of the American alligator and the American crocodile in the lower Florida Keys. Florida Field Nat 1983, 11:1-24.

25. Tamarack JL: Georgia's Coastal Island Alligators, Variations and Prey Availability. In Proceedings of 8th Working Meeting of the Crocodile Specialist Group, IUCN, 13-18, 1986. Quito, Ecuador: 1986:105-117.

26. Nifong JC, Nifong RL, Silliman BR, Lowers RH, Guillette $L J$ Jr, Ferguson JM, Welsh M, Abernathy K, Marshall G: Animal-borne imaging reveals novel insights into the foraging behaviors and diel activity of a large-bodied apex predator, the American alligator (Alligator mississippiensis). PLoS One 2014, 9:e83953.

27. Mazzotti FJ, Dunson WA: Osmoregulation in crocodilians. Am Zool 1989, 29:903-920.

28. Goodwin TM, Marion WR: Seasonal activity ranges and habitat preferences of adult alligators in a north-central Florida lake. $J$ Herpetol 1979, 13:157-163.

29. Jacobsen T, Kushlan JA: Growth dynamics in the American alligator (Alligator mississippiensis). J Zool 1989, 219:309-328.

30. Berthold P, Terrill SB: Recent advances in studies of bird migration. Annu Rev Ecol Syst 1991, 22:357-378.

31. Mate BR, Nieukirk SL, Kraus SD: Satellite-monitored movements of the northern right whale. J Wild Manage 1997, 61:1393-1405.

32. Breed GA, Jonsen ID, Myers RA, Bowen WD: Sex-specific, seasonal foraging tactics of adult grey seals (Halichoerus grypus) revealed by state-space analysis. Ecology 2009, 90:3209-3211.

33. Godley BJ, Blumenthal JM, Broderick AC, Coyne MS, Godfrey MH, Hawkes $L A$, Witt MJ: Satellite tracking of sea turtles: Where have we been and where do we go next? Endang Species Res 2008, 4:3-22.

34. Hart KM, Hyrenbach KD: Satellite telemetry of marine megavertebrates: the coming of age of an experimental science. Endanger Species Res 2009, 10:9-20.

35. Witt MJ, Bonguno EA, Borderick AC, Coyne MS, Formia A, Gibudi A, Mounguengui GAM, Moussounda C, Safou MN, Mougessono S, Parnell RJ, Sounguet $G$, Verhage $S$ : Tracking leatherback turtles from the world's largest rookery: assessing threats across the South Atlantic. Proc $R$ SOC $B$ 2011, 278:2338-2347.

36. Lance VA, Elsey RM, Trosclair PL III, Nunez LA: Long-distance movement by American alligators in southwest Louisiana. Southeast Nat 2011, 10:389-398. 
37. Tomkiewicz SM, Fuller MR, Kie JG, Bates KK: Global positioning system and associated technologies in animal behaviour and ecological research. Phil Trans R Soc B 2010, 365:2163-2176.

38. Ogden J, Davis S: A Comparison of Wading Bird Nesting Colony Dynamics (1931-1946 and 1974-1989) as an Indication of Ecosystem Conditions in the Southern Everglades. In Everglades: The Ecosystem and Its Restoration. Edited by Davis D, Ogden J. Delray Beach, FL: St. Lucie Press; 1994:533-570

39. Davis SM, Childers DL, Lorenz JJ, Wanless HR, Hopkins TE: A conceptual model of ecological interactions in the mangrove estuaries of the Florida Everglades. Wetlands 2005, 25:832-842.

40. Mazzotti FJ: The Ecology of Crocodylus acutus in Florida. Ph.D. thesis. University Park, PA: The Pennsylvania State University; 1983.

41. Brien ML, Read MA, McCallum HI, Grigg GC: Home range and movements of radio-tracked estuarine crocodiles (Crocodylus porosus) within a non-tidal waterhole. Wildl Res 2008, 35:140-149.

42. Coyne MS, Godley BJ: Satellite Tracking and Analysis Tool (STAT): an integrated system for archiving, analyzing and mapping animal tracking data. Mar Ecol Prog Ser 2005, 301:1-7.

43. CLS: Argos user's Manual: Worldwide Tracking and Environmental Monitoring by Satellite. Toulouse: CLS; 2011. 19 August 2011 update.

44. Hooge PN, Eichenlaub W, Hooge ER: Animal Movement 2.5. Anchorage, AK: US Geological Survey, Alaska Biological Science Center; 2001.

45. Seaman DE, Power RA: An evaluation of the accuracy of kernel density estimators for home range analysis. Ecology 1996, 77:2075-2085.

46. Hart KM, Lamont MM, Sartain AR, Fujisaki I, Stephens BS: Movements and habitat-use of loggerhead sea turtles in the northern Gulf of Mexico during the reproductive period. PLoS One 2013, 8:e66921.

47. Rodgers AR, Carr AP, Smith L, Kie JG: HRT: Home Range Tools for ArcGIS. Ontario: Ontario Ministry of Natural Resources, Centre for Northern Forest Ecosystem Research; 2005.

48. Burnham KP, Anderson DR: Model Selection and Multimodel Inference: $A$ Practical Information-Theoretic Approach. New York: Springer; 2002.

Cite this article as: Fujisaki et al:: Home range and movements of American alligators (Alligator mississippiensis) in an estuary habitat. Animal Biotelemetry 2014 2:8.

\section{Submit your next manuscript to BioMed Central and take full advantage of:}

- Convenient online submission

- Thorough peer review

- No space constraints or color figure charges

- Immediate publication on acceptance

- Inclusion in PubMed, CAS, Scopus and Google Scholar

- Research which is freely available for redistribution 